\title{
Potential link between genetic polymorphisms of catechol-O-methyltransferase and dopamine receptors and treatment efficacy of risperidone on schizophrenia
}

This article was published in the following Dove Press journal:

Neuropsychiatric Disease and Treatment

Jiyang Han'

Yan $\mathrm{Li}^{2}$

Xumei Wang'

'Department of Psychiatry, Shengjing Hospital of China Medical University, Shenyang, Liaoning, China; ${ }^{2}$ Department of Cell Biology, Key Laboratory of Cell Biology, Ministry of Public Health, China Medical University, Shenyang, Liaoning, China
Objective: The current study aimed to explore the association of single nucleotide polymorphisms (SNPs) within catechol-O-methyltransferase (COMT) and dopamine receptors with schizophrenia and genetic association with risperidone treatment response.

Methods: A total of 690 schizophrenic patients (case group) were selected and 430 healthy people were included as the controls. All patients received risperidone treatment continuously for 8 weeks. Next, peripheral venous blood samples were collected and were subjected to polymerase chain reaction-restriction fragment length polymorphism to amplify and genotype the SNPs within COMT and dopamine receptors. Then, correlation analysis was conducted between Positive and Negative Syndrome Scale improvement rates and SNPs within COMT and the dopamine receptor gene.

Results: The allele of $D R D 1$ rs11749676 (A) emerged as a key element in reducing schizophrenia risk with statistical significance $(P<0.001)$. Remarkably, alleles of COMT rs165774 (G), DRD2 rs6277 (T), and DRD3 rs6280 (C) were associated with raised predisposition to schizophrenia (all $P<0.001$ ). Regarding DRD1 rs11746641, DRD1 rs11749676, DRD2 rs6277, and DRD3 rs6280, the case group exhibited a lesser frequency of heterozygotes in comparison with wild homozygotes genotype (all $P<0.001$ ). SNPs (COMT rs4680, DRD2 rs6275, DRD2 rs1801028, and $D R D 2$ rs6277) were remarkably associated with improvement rates of PANSS total scores $(P<0.05)$. SNPs $(C O M T$ rs 165599 and DRD2 rs1801028) were significantly associated with risperidone efficacy on negative symptoms $(P<0.05)$.

Conclusion: COMT SNPs and dopamine receptor SNPs were correlated with prevalence of schizophrenia and risperidone treatment efficacy of schizophrenia.

Keywords: schizophrenia, catechol-O-methyltransferase, dopamine receptor gene, single nucleotide polymorphisms, risperidone

\section{Introduction}

Schizophrenia is a chronic and devastating mental disorder, afflicting about $0.7 \%$ of the world population. ${ }^{1}$ Its symptoms are generally divided into positive forms (eg, hallucinations, delusions, and disorganized behaviors) and negative forms (eg, anhedonia, alogia, and apathy). ${ }^{2-4}$ Risperidone,${ }^{5}$ the most commonly prescribed antipsychotic in China, ${ }^{6}$ has been reported to be desirable for treating both positive and negative symptoms of schizophrenia. ${ }^{7}$ Also risperidone was effective and generally well tolerated in Chinese patients. ${ }^{8}$ In particular, risperidone and its active metabolites (eg, 9-hydroxyrisperidone) can exert anxiolytic and antidepressant effects by blocking
Correspondence: Xumei Wang Department of Psychiatry, Shengjing Hospital of China Medical University, Number 36 Sanhao Street, Heping District, Shenyang, Liaoning I 10004 China

Tel +86248328 2003

Fax +86248328 2645

Email tai_san@I26.com 
dopamine D2 and serotonin 5-HT2 receptors in the CNS. ${ }^{9}$ Nevertheless, the efficacy of the drug treatment is still far from satisfaction, so the inherent causes of schizophrenia should be continuously studied.

The most widely accepted neurochemical hypothesis of schizophrenia is the dopamine hypothesis, which assumes that symptoms of schizophrenia may result from excessive dopaminergic neurotransmission in mesolimbic and striatal brain regions. The abnormal distribution of dopamine has been linked with the pathophysiological mechanism of action underlying schizophrenia. ${ }^{10}$ So dopamine receptors are considered the target of neurologic drugs for their mediation of dopamine signal transduction. ${ }^{11,12}$ Currently, polymorphisms of several dopamine receptor subtypes have been documented to be associated with the therapeutic effects of risperidone. ${ }^{13-15}$ Previous studies also manifested that risperidone is a selective monoaminergic antagonist for DRD2 and patients with different types of $D R D 2$ polymorphisms present varying responses to risperidone. ${ }^{16}$ In addition, recent studies have also indicated that the dysfunction of $D R D 1$ in the prefrontal cortex may cause cognitive defects and the negative symptoms of schizophrenia. ${ }^{17}$ However, a study on a patient with comorbid intellectual disability, catatonic schizophrenia, and oneiroid syndrome showed that $D R D 1$ polymorphisms may be unrelated to the efficacy of risperidone. ${ }^{18}$ Therefore, it remains unclear whether dopamine receptor polymorphisms are involved in the mechanism of risperidone for schizophrenia patients.

Furthermore, catechol-O-methyltransferase (COMT) may deactivate dopamine via methyl conjugation. ${ }^{19}$ Due to a G-A transition in the COMT that maps into chromosome $22 q 11$, Val allele of the enzyme has been discovered to induce high enzymatic activity, resulting in lower dopamine levels in the prefrontal cortex. ${ }^{20}$ Based on the importance of dopamine in the development of schizophrenia, it was hypothesized that mutations of COMT polymorphisms may contribute to different treatment efficacy of risperidone for schizophrenia patients.

Psychiatric Genomic Consortium (PGC) identified a large number of schizophrenia-associated risk loci through genome-wide association study (GWAS), and this provides targets influencing susceptibility to schizophrenia. ${ }^{21}$ Therefore, the current study was performed to analyze the relationship between single nucleotide polymorphisms (SNPs) within dopamine receptors/COMT and positive and negative syndrome scale (PANSS) improvement rate of risperidone monotherapy in Chinese patients with schizophrenia.

\section{Materials and methods Subjects}

A total of 690 schizophrenic patients (case group) were selected from the Department of Psychiatry, Shengjing Hospital of China Medical University from May 2008 to September 2016, and they were analyzed. Four hundred and thirty healthy people recruited from the community were included at the same time to be the control group. The patients would be included if: 1) they were diagnosed as schizophrenic by senior doctors and other psychiatric comorbidities were screened out by two psychiatrists after necessary examinations; 2) they conformed to the diagnostic criteria enacted by the Chinese Classification of Mental Disorders and Diagnostic Criteria Version 3 (CCMD-3); 3 ) their PANSS total scores were $\geq 70$ but $\leq 120$ at the time of screening; 4) their psychotic symptoms first appeared 3-60 months ago; 5) they were of Han ethnic population ranging from 18 to 40 years old; 6) they had not received any antipsychotic treatments within the last 2 months before admission; 7) they had no history of abusing psychoactive substances; 8) they did not have disorders related to central nervous system or any other serious physical illness; 9) they did not have any personality disorder or mental retardation; and 10) they would be staying in hospital during the period of treatment. Patients were receiving atypical antipsychotic drug treatment for the first time. All patients provided written informed consent for inclusion in this study. This research obtained approval from the ethics committee of Shengjing Hospital of China Medical University.

\section{Clinical treatment}

Before risperidone monotherapy treatment, all patients were subjected to at least a 4-week medication washout period. Risperidone was given at an initial dose of $2 \mathrm{mg}$ /day administered by the prescribing clinicians. Then the trial employed a gradual dosing in the first 2 weeks, which became flexible up to 8 weeks. All patients received risperidone (Xian-Janssen Pharmaceutical Ltd., Shaanxi Sheng, China) continuously for 8 weeks with the initial dose of $1 \mathrm{mg} /$ day. Then the medications were adjusted to the therapeutic amount (ie, 2-6 mg/day), according to individual tolerance dosage of patients. Medication compliance was closely monitored and identified by the nursing staff. During the medication period, no other drugs were administered except biperiden for moderate extrapyramidal symptoms (EPS), flunitrazepam for acute insomnia, and sennoside for constipation. Benzodiazepines were applied when necessary, but prophylactic benzhexol was not administered. The medications were 
stopped when serious side effects were presented or diseases deteriorated.

\section{SNP selection}

According to previously published investigations, we selected potential SNPs, including COMT rs165599, moderately associated with a change in the PANSS Negative score; ${ }^{22}$ COMT rs4680, which might be relevant in the differentiation of schizophrenic subtypes, ${ }^{23}$ COMT rs165774, involved as a genetic risk factor for schizophrenia; ${ }^{24} D R D 1$ rs11746641, associated with protection against the risk of developing schizophrenia; ${ }^{25}$ DRD1 rs11749676, supported the role of dopamine dysfunction; ${ }^{25}$ DRD2 rs6275, implicated in schizophrenia, ${ }^{26} D R D 2$ rs 1801028 , reported as a risk locus for schizophrenia; ${ }^{27} D R D 2$ rs6277, regarded as the only susceptibility factor for schizophrenia; ${ }^{28} D R D 3$ rs6280, reported to be associated with altered dopamine binding affinity; ${ }^{29}$ and DRD5 rs6283, associated with male paranoid schizophrenia patients. ${ }^{30}$ Since these SNPs have been proved to be associated with changes in the PANSS score in published studies, they were selected as genetic targets for schizophrenia in our study. DRD4 was not included as it is rarely marked among the Chinese population. ${ }^{31}$

\section{Isolation of genomic DNA}

Peripheral venous blood $(5 \mathrm{~mL})$ was collected from each subject at the beginning of the treatment for genotyping.
EDTA solution was prepared for usage. Genomic DNA was isolated manually by means of the standard phenolchloroform extraction.

\section{Amplification and genotyping of COMT genetic fragments}

We conducted cleaved amplification polymorphism of sequence-tagged sites by polymerase chain reaction-restriction fragment length polymorphism (PCR-RELF) to amplify and genotype for COMT from the genomic DNA enzyme treatment. NIaIII was applied as the restriction enzyme to COMT. The primer sequences are shown in Table 1. The conditions for PCR were: 1) denaturation for 8 minutes at $94^{\circ} \mathrm{C}$; 2) 35 cycles in the following sequence: 1 minute at $94^{\circ} \mathrm{C}, 45$ seconds at $57^{\circ} \mathrm{C}, 45$ seconds at $72^{\circ} \mathrm{C}$, and finally 8 minutes for extension at $72^{\circ} \mathrm{C}$ (Eppendorf, Hamburg, Germany); 3) purification of the PCR products; 4) usage of the restriction fragment length polymorphism (RFLP) for genotyping.

\section{Amplification and genotyping of dopamine receptor genes}

PCR-RELF was also applied to amplify and genotype dopamine receptors with the primer sequences shown in Table 1. SphI was applied as the restriction enzyme for dopamine receptors. The PCR reactions were performed as follows: denaturation for 8 minutes at $94^{\circ} \mathrm{C}$, annealing for 30 seconds at $55^{\circ} \mathrm{C}$, and extension for 60 seconds at $72^{\circ} \mathrm{C}$. We conducted

Table I The primer sequences of genetic polymorphisms

\begin{tabular}{|c|c|c|}
\hline SNP & Gene sequence & Primer sequence \\
\hline \multirow[t]{2}{*}{ COMT rsI65599 A>G } & GACGACTGCC[A/G]GCCTGGGAAA & F: 5'-TCGTGGACGCCGTGATTCAGG-3' \\
\hline & & R: 5'-AGGTCTGACAACGGGTCAGGC-3' \\
\hline \multirow[t]{2}{*}{ COMT rs4680 G $>A$} & TTTCGCTGGC[A/G]TGAAGGACAA & F: 5'-GGATGATGGA2TTTCGCTCGC-3' \\
\hline & & R: 5'-CTGGTGGGTAGGACAAAGTGC-3' \\
\hline \multirow[t]{2}{*}{ COMT rsI65774 A>G } & GTTAGCAGCC[A/G]GACTAGGAGC & F: 5'-GCTTAAGGAGCCTCACATCAGT-3' \\
\hline & & R: 5'-CTAGTGCTGGTTCCTTCCAATC-3' \\
\hline \multirow[t]{2}{*}{ 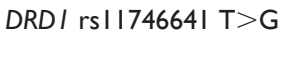 } & GAAGGTGTAT[G/T]GAATTTTATA & F: 5'-CTGATATGGTGCATGGCTGTT-3' \\
\hline & & R: 5'-ACCTGCGTTGTCTCCAAGTGT-3' \\
\hline \multirow[t]{2}{*}{$D R D /$ rsII $749676 \mathrm{G}>\mathrm{A}$} & AGAAAGAAAA[A/G]GCATCATGCT & F: 5'-GGACACTTGGAGACAACGCAG-3' \\
\hline & & R: 5'-ATGAGCAGCGACAGGAAACAG-3' \\
\hline \multirow[t]{2}{*}{$D R D 2$ rs6275 C>T } & CGTCCCACCA[C/T]GGTCTCCACA & F: 5'-ATGGGTGGCTGATGCCTGGG-3' \\
\hline & & R: 5'-GGTCTTTGGGCATGCCCATTCT-3' \\
\hline \multirow[t]{2}{*}{$D R D 2$ rsI80I028 C>G } & CCCGACCCGT[C/G]CCACCACGGT & F: 5'-CCAGCTGACTCTCCCCGACCGGT-3' \\
\hline & & R: 5'-TTGGGCATGGTCTGGATCTCAAA-3' \\
\hline \multirow[t]{2}{*}{$D R D 2$ rs6277 C>T } & ACAGCACTCC[C/T]GACAGCCCCG & F: 5'-GCCACCACGGCTGGCCAAGTTGTCTA-3' \\
\hline & & R: 5'-GAGGAGCACCTTCCTGAGTGTCATCA-3' \\
\hline \multirow[t]{2}{*}{ DRD3 rs6280 T>C } & TTCAGGTGGC[C/T]ACTCAGCTGG & F: 5'-GCTCTATCTCCAACTCTCACA-3' \\
\hline & & R: 5'-AAGTCTACTCACCTCCAGGTA-3' \\
\hline \multirow[t]{2}{*}{$D R D 5$ rs6283 $\mathrm{T}>\mathrm{C}$} & GTGGACACCC[C/T]GAAGGCCCTC & F: 5'-GAGGGTCCCTTGGCTGAG-3' \\
\hline & & R: 5'-CCCTCTCCAGGGAGGAAATC-3' \\
\hline
\end{tabular}

Abbreviations: COMT, catechol-O-methyltransferase; DRDI, dopamine receptor DI; DRD2, dopamine receptor D2; DRD3, dopamine receptor D3; DRD5, dopamine receptor D5; F, forward; R, reverse; SNP, single nucleotide polymorphism. 
the PCR reactions for 35 cycles and then the extension for 10 minutes at $72^{\circ} \mathrm{C}$. Finally, we terminated the reaction at $4^{\circ} \mathrm{C}$ and maintained the samples for cryopreservation.

\section{Evaluation of PANSS improvement rates}

PANSS is an internationally accepted scale used to quantify clinical signs of schizophrenia, and patients are rated from 1 to 7 on 30 different symptoms based on the interviews as well as reports of family members or primary care hospital workers. The following formula was used to calculate the corresponding PANSS improvement rate for each patient:

PANSS improvement rate

$$
=\frac{(\text { PANSS at week } 0)-(\text { PANSS at week } 8)}{\text { PANSS at week } 0}
$$

If the results of the correlation analysis are significant, then a specific SNP is associated with an enhanced efficacy of risperidone for schizophrenia patients.

Before study initiation, all investigators received standardized training on the use of all scoring systems utilized in this study to ensure consistency of scoring.

\section{Statistical analysis}

Data analysis was performed using IBM SPSS Statistics for Windows, Version 21.0 (IBM Corp., Armonk, NY, USA). Measurement data were expressed in the form of mean \pm standard deviation. Data between two groups were calculated by Student's $t$-test. Chi-square test was performed to assess the association between categorical variables of clinicopathological parameters. One-way analysis of variance with Bonferroni correction was applied to analyze the association between the PANSS improvement rates and the genotypes. Five genetic models were established, including allelic model (M/W), heterozygous model (MW/WW), homozygous model (MM/WW), dominant model ([MW+MM]/WW), and recessive model $(\mathrm{MM} /[\mathrm{MW}+\mathrm{WW}])$. W represented wild allele and $\mathrm{M}$ represented mutant allele. Multiple logistic regression analysis followed by stepwise backward selection process $(P=0.10)$ was used to evaluate associations between SNPs and schizophrenia risk under five genetic models. Hardy-Weinberg equilibrium test was performed to observe if subjects conformed to law of genetic equilibrium. As there were 10 SNPs investigated here, Bonferroni correction was applied, and $P<0.005$ was considered as statistical significance when odds ratios (ORs) were calculated; otherwise, $P<0.05$ was considered as statistical significance.

\section{Results}

\section{Baseline characteristics of patients in the case and control groups}

Clinical and demographic characteristics of patients were revealed and compared in Table 2 . The case group included a total of 690 schizophrenia patients (398 males and 292 females). The case group included a total of 501 smokers and another 384 patients who usually consumed alcohol. Another 308 smokers and 235 individuals with a history of alcohol consumption were included in the control group. No significant difference in age, gender, and height existed between the case and the control groups $(P>0.05)$. It was also concluded from chi-square test that case and control groups have similar sex ratio as well as frequencies of smoking and drinking history $(P>0.05)$.

\section{Genotype distribution and allele frequency of COMT and dopamine receptor gene loci in the case and control groups}

As for COMT, there existed little difference in the distribution among genotyping frequencies of rs165599 and rs4680 (ie, GG, GA, and AA; Table 3). However, the G allele of COMT rs165774 was associated with increased risk of schizophrenia when compared with A allele $(\mathrm{OR}=2.05,95 \%$ CI: $1.63-2.57, P<0.001$, Table 4).

When it comes to DRD1 rs11746641, rs11749676, $D R D 2$ rs6277, and DRD3 rs6280, the case group exhibited a lesser frequency of heterozygotes in comparison with wild homozygotes genotype (Table 3 ). In the allelic model

Table 2 The clinical baseline characteristics

\begin{tabular}{llll}
\hline Characteristics & $\begin{array}{l}\text { Case group } \\
(\mathbf{n}=690)\end{array}$ & $\begin{array}{l}\text { Control group } \\
(\mathbf{n}=\mathbf{4 3 0})\end{array}$ & P-value \\
\hline $\begin{array}{l}\text { Age (years) } \\
\text { Gender }\end{array}$ & $27.2 \pm 3.5$ & $26.9 \pm 3.1$ & $0.146^{\mathrm{a}}$ \\
$\quad$ Male & $398(57.68 \%)$ & $231(53.72 \%)$ & $0.194^{\mathrm{b}}$ \\
$\quad$ Female & $292(42.32 \%)$ & $199(46.28 \%)$ & \\
Weight (kg) & $67.2 \pm 3.5$ & $66.9 \pm 3.4$ & $0.159^{\mathrm{a}}$ \\
Height (cm) & $167.4 \pm \mathrm{II.5}$ & $166.9 \pm \mathrm{II} .2$ & $0.475^{\mathrm{a}}$ \\
Smoking & & & \\
$\quad$ Yes & $501(72.61 \%)$ & $308(71.63 \%)$ & $0.72 \mathrm{I}^{\mathrm{b}}$ \\
$\quad$ No & $189(27.39 \%)$ & $122(28.37 \%)$ & \\
Drinking & & & \\
$\quad$ Yes & $384(55.65 \%)$ & $235(54.65 \%)$ & $0.743^{\mathrm{b}}$ \\
No & $306(44.35 \%)$ & $195(45.35 \%)$ & \\
\hline
\end{tabular}

Notes: ${ }^{a}$ Student's $t$-test. ${ }^{b} \mathrm{Chi}$-square test. 'Participants who drank more than three times per week for over 5 years with the amount of alcohol $\geq 20 \mathrm{~g}$ each time recognized as "yes", and participants who never drank or occasionally drank with the amount of alcohol $<20 \mathrm{~g}$ recognized as "no". Age, weight, and height data presented as mean \pm standard deviation. 
Table 3 Genotype frequencies of SNPs within COMT, DRDI, DRD2, DRD3, and DRD5

\begin{tabular}{|c|c|c|c|}
\hline Gene & $\begin{array}{l}\text { Genotype } \\
(\mathbf{W}>\mathbf{M})\end{array}$ & $\begin{array}{l}\text { Control } \\
(n=430)\end{array}$ & $\begin{array}{l}\text { Cases } \\
(n=690)\end{array}$ \\
\hline \multirow[t]{18}{*}{ COMT } & rsI65599 A & & \\
\hline & $\mathrm{AA}$ & 139 (32.32\%) & $212(30.72 \%)$ \\
\hline & AG & 231 (53.72\%) & 367 (53.19\%) \\
\hline & GG & 60 (13.96\%) & $111(16.19 \%)$ \\
\hline & $\chi^{2}$ & Ref & 1.020 \\
\hline & $P$-value & Ref & 0.600 \\
\hline & $\mathrm{rs} 4680 \mathrm{G}>$ & & \\
\hline & GG & $211(49.07 \%)$ & 297 (43.04\%) \\
\hline & GA & I 72 (40.00\%) & 310 (44.93\%) \\
\hline & $\mathrm{AA}$ & $47(10.93 \%)$ & $83(12.03 \%)$ \\
\hline & $\chi^{2}$ & Ref & 3.891 \\
\hline & $P$-value & Ref & 0.143 \\
\hline & rsI65774 G & & \\
\hline & GG & 317 (73.72\%) & 399 (57.83\%) \\
\hline & AG & 106 (24.65\%) & $238(34.49 \%)$ \\
\hline & AA & 7 (I.63\%) & 53 (7.68\%) \\
\hline & $\chi^{2}$ & Ref & 36.94 \\
\hline & $P$-value & Ref & $<0.001$ \\
\hline \multirow[t]{12}{*}{ DRDI } & rsII74664I & & \\
\hline & TT & 311 (72.32\%) & 354 (5I.30\%) \\
\hline & TG & II 3 (26.28\%) & $283(4 \mid .01 \%)$ \\
\hline & GG & $6(1.40 \%)$ & 53 (7.69\%) \\
\hline & $\chi^{2}$ & Ref & 55.85 \\
\hline & $P$-value & Ref & $<0.001$ \\
\hline & rsII749676 & & \\
\hline & GG & I52 (35.34\%) & 387 (56.09\%) \\
\hline & GA & $211(49.07 \%)$ & 238 (34.49\%) \\
\hline & $\mathrm{AA}$ & 67 (I5.59\%) & $65(9.42 \%)$ \\
\hline & $\chi^{2}$ & Ref & 46.25 \\
\hline & $P$-value & Ref & $<0.001$ \\
\hline \multirow[t]{18}{*}{ DRD2 } & rs6275 C> & & \\
\hline & $\mathrm{CC}$ & $86(20.00 \%)$ & I 54 (22.32\%) \\
\hline & CT & $211(49.07 \%)$ & 335 (48.55\%) \\
\hline & TT & I 33 (30.93\%) & 201 (29.13\%) \\
\hline & $\chi^{2}$ & Ref & 0.967 \\
\hline & $P$-value & Ref & 0.617 \\
\hline & rs 1801028 & & \\
\hline & $\mathrm{CC}$ & 396 (92.09\%) & 632 (9l.59\%) \\
\hline & CG & 26 (6.05\%) & $5 \mathrm{I}(7.39 \%)$ \\
\hline & GG & $8(1.86 \%)$ & 7 (I.02\%) \\
\hline & $\chi^{2}$ & Ref & 2.12 \\
\hline & $P$-value & Ref & 0.346 \\
\hline & rs6277 C> & & \\
\hline & $\mathrm{CC}$ & 410 (95.35\%) & $554(80.29 \%)$ \\
\hline & $\mathrm{CT}$ & $13(3.02 \%)$ & $109(15.80 \%)$ \\
\hline & TT & 7 (I.63\%) & 27 (3.91\%) \\
\hline & $\chi^{2}$ & Ref & 51.22 \\
\hline & $P$-value & Ref & $<0.001$ \\
\hline \multirow[t]{6}{*}{ DRD3 } & $\mathrm{rs} 6280 \mathrm{~T}>\mathrm{C}$ & & \\
\hline & TT & 363 (84.42\%) & $418(60.58 \%)$ \\
\hline & $\mathrm{TC}$ & $46(10.70 \%)$ & 212 (30.72\%) \\
\hline & $\mathrm{CC}$ & 21 (4.88\%) & 60 (8.70\%) \\
\hline & $\chi^{2}$ & Ref & 10.489 \\
\hline & $P$-value & Ref & $<0.001$ \\
\hline
\end{tabular}

Table 3 (Continued)

\begin{tabular}{llll}
\hline Gene & $\begin{array}{l}\text { Genotype } \\
(\mathbf{W}>\mathbf{M})\end{array}$ & $\begin{array}{l}\text { Control } \\
(\mathbf{n}=\mathbf{4 3 0})\end{array}$ & $\begin{array}{l}\text { Cases } \\
\mathbf{( n = 6 9 0 )}\end{array}$ \\
\hline DRD5 & rs6283 T>C & & \\
& TT & $145(33.72 \%)$ & $212(30.72 \%)$ \\
& TC & $218(50.70 \%)$ & $348(50.43 \%)$ \\
& CC & $67(15.58 \%)$ & $130(18.85 \%)$ \\
& $\chi^{2}$ & Ref & 2.350 \\
& $P$-value & Ref & 0.309 \\
\hline
\end{tabular}

Abbreviations: COMT, catechol-O-methyltransferase; DRDI, dopamine receptor DI; DRD2, dopamine receptor D2; DRD3, dopamine receptor D3; DRD5, dopamine receptor D5; M, mutant allele; Ref, Reference; SNP, single nucleotide polymorphism; $\mathrm{W}$, wild allele.

(Table 4), DRD1 rs11749676 (G>A) was prominently associated with declined schizophrenia risk $(\mathrm{OR}=0.54,95 \%$ CI: $0.45-0.65, P<0.001)$, while DRD2 rs6277 $(\mathrm{C}>\mathrm{T})$ and $D R D 3$ rs6280 $(\mathrm{T}>\mathrm{C})$ were both correlated with elevated susceptibility to schizophrenia (OR $=4.13,95 \%$ CI: $2.72-6.27$, $P<0.001$; OR $=2.78,95 \%$ CI: $2.16-3.58, P<0.001)$. Besides, the heterozygotes of $D R D 1 \mathrm{rs} 11749676(\mathrm{G}>\mathrm{A})$ appeared to confer a lower possibility of schizophrenia risk than their wild homozygotes (GA vs GG, OR $=0.38,95 \%$ CI: $0.26-0.56$, $P<0.001)$. In addition, the mutant genotype of DRD1 rs11746641 $(\mathrm{T}>\mathrm{G})$ appeared to confer subject-regulated possibility of schizophrenia risk than its wild homozygotes (GG vs TT, OR =7.76, 95\% CI: 3.29-18.30, $P<0.001$ ). Notably, the crucial role of $D R D 1$ rs11746641 (T>G), DRD2 rs6277 (C>T), and DRD3 rs6280 (T>C) in increasing risk of schizophrenia was also enhanced by dominant model (TG+GG vs TT, OR $=2.48,95 \%$ CI: $1.92-3.21, P<0.001$; CT+TT vs CC, $\mathrm{OR}=5.03,95 \%$ CI: $3.09-8.18, P<0.001$; $\mathrm{TC}+\mathrm{CC}$ vs TT, $\mathrm{OR}=3.53,95 \%$ CI: $2.61-4.77, P<0.001)$.

\section{Association of PANSS score with SNPs situated in COMT and dopamine receptors}

The COMT rs 4680 displayed a significant association with PANSS total improvement rates $(P<0.05)$, while rs 165599 was associated with PANSS negative scores $(P<0.05$, Table 5). Nonetheless, COMT rs165774 seemed to play hardly any role in regulating the treatment efficacy of risperidone on schizophrenia (all $P>0.05$ ).

In addition, three SNPs of DRD2, including rs6275, rs1801028, and rs6277, showed significant associations with PANSS total improvement rates $(P<0.05)$ (Table 5). Also, $D R D 2$ rs 1801028 was associated with PANSS negative scores $(P<0.05)$. Nonetheless, four SNPs located in dopamine receptor gene (rs11746641, rs11749676, rs6280, and 


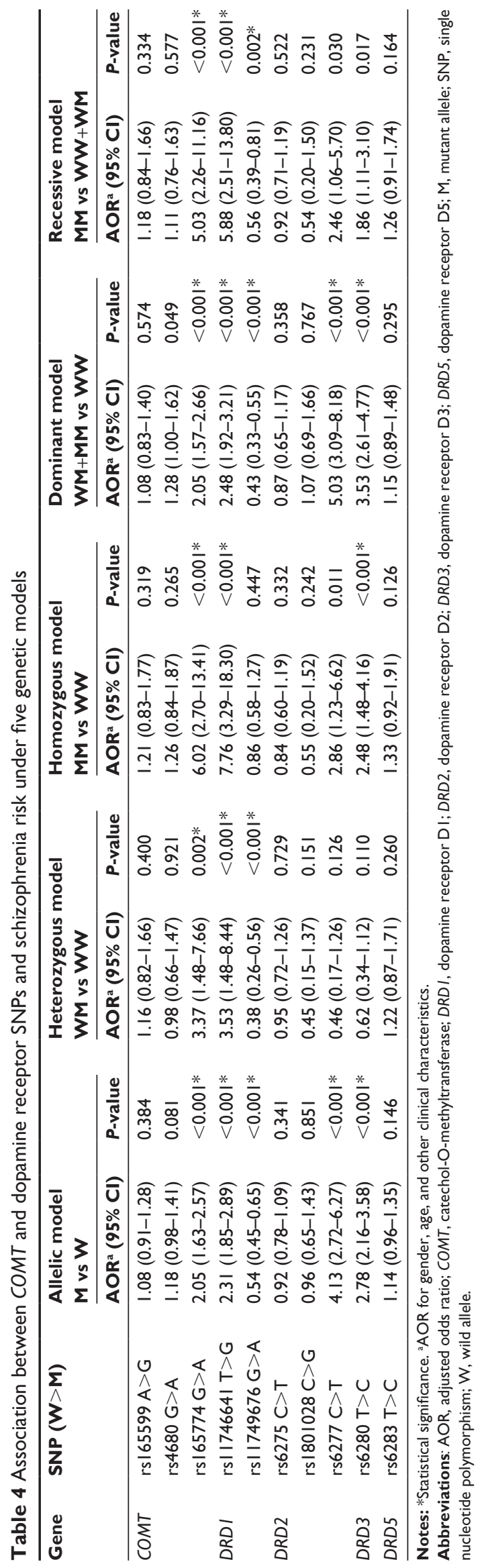

rs6283) exerted no effects on regulating the treatment efficacy of risperidone for schizophrenia (all $P>0.05$ ).

\section{Discussion}

In this study, we examined the effect of SNPs within dopamine receptor gene/COMT on risperidone treatment response in correlation analysis. The overall efficacy of antipsychotic drugs has been improved since selection of an appropriate medication has been emphasized by studies, which established a potential link between SNPs and the efficacy of medications..$^{32}$ In particular, our study has provided the evidence for negative association of COMT and $D R D 1$ polymorphisms with treatment response to risperidone in the Han Chinese schizophrenia patients.

In this study, we discovered that mutations of certain functional polymorphisms (rs165599, rs4680, and rs165774) situated in COMT and certain functional polymorphisms situated in dopamine receptor genes (DRD1 rs11746641, DRD1 rs11749676, DRD2 rs6275, DRD2 rs1801028, DRD2 rs6277, DRD3 rs6280, and DRD5 rs6283) would modify risk of schizophrenia in this Chinese population. It was widely accepted that SNPs situated in COMT would affect its enzyme (Val and Met) activity, which played a significant role in altering hypo-dopaminergic states of patients and activity of the frontal lobes within human beings. ${ }^{19,33}$ Hence, rs165774 of COMT was convincingly regarded as the promising susceptible locus for schizophrenia risk.

As for the dopamine receptor gene family, the large G-protein coupled receptor superfamily mainly mediated actions of dopamine, controlling cognitive ability, neuroendocrine secretion, and so on. Consistent with study results, diverse SNPs of dopamine receptor gene have also been confirmed as susceptible parameters for schizophrenia. ${ }^{25,30,34}$ In addition, we discovered that patients with SNP COMT rs4680 AG and AA genotypes exhibited an enhanced overall improvement rate of PANSS compared with GG genotypes. Tybura et al found that three antipsychotics (perazine, ziprasidone, and olanzapine) did not differ in terms of reduction of the PANSS score or retention rate at the follow-up. ${ }^{35}$ They claimed that there was no interaction between COMT and DRD2 polymorphisms and response to the antipsychotic treatment. ${ }^{35}$ However, the number of patients included in the study was small, and the patients did not administer the antipsychotic medication risperidone we used in our study. We suspected that polymorphisms were likely to affect the treatment response to risperidone. Nevertheless, the negative findings of this study suggested that the effect of variations in COMT and DRD2 genes on the therapeutic 
Table 5 Association of SNPs situated in COMT and DRD2 with PANSS improvement rates of schizophrenia after treatment with risperidone

\begin{tabular}{|c|c|c|c|c|c|c|c|c|}
\hline \multirow[t]{2}{*}{ Gene } & \multirow{2}{*}{$\begin{array}{l}\text { Genotype } \\
(W>M)\end{array}$} & \multirow{2}{*}{$\begin{array}{l}\text { Participants } \\
\text { (n) }\end{array}$} & \multicolumn{6}{|c|}{ Improvement rate (\%) } \\
\hline & & & $\begin{array}{l}\text { PANSS total, } \\
\text { mean } \pm \text { SD }\end{array}$ & $P$-value & $\begin{array}{l}\text { PANSS negative, } \\
\text { mean } \pm \text { SD }\end{array}$ & $P$-value & $\begin{array}{l}\text { PANSS positive, } \\
\text { mean } \pm \text { SD }\end{array}$ & $P$-value \\
\hline \multirow[t]{12}{*}{ COMT } & \multicolumn{2}{|l|}{$r s 4680 \mathrm{G}>A$} & & $<0.001 *$ & & 0.421 & & 0.051 \\
\hline & GG & 297 & $15.64 \pm 12.58$ & & $25.08 \pm 16.33$ & & $13.07 \pm 16.52$ & \\
\hline & GA & 310 & $25.23 \pm 14.40 * *$ & & $26.79 \pm 17.06$ & & $14.65 \pm 16.14$ & \\
\hline & AA & 83 & $22.32 \pm 13.16^{* *}$ & & $25.25 \pm 16.07$ & & $17.92 \pm 15.37$ & \\
\hline & \multicolumn{2}{|c|}{$\mathrm{rs} 165599 \mathrm{~A}>\mathrm{G}$} & & 0.287 & & $<0.00 I^{*}$ & & 0.392 \\
\hline & $\mathrm{AA}$ & 212 & $25.00 \pm 15.84$ & & $|3.3| \pm \mid 2.85$ & & $19.74 \pm 17.76$ & \\
\hline & AG & 367 & $26.90 \pm 16.62$ & & $24.32 \pm|3.2|^{* *}$ & & $17.74 \pm 17.06$ & \\
\hline & GG & 111 & $24.76 \pm 17.18$ & & $21.39 \pm 14.23 * *$ & & $\mid 8.41 \pm 14.67$ & \\
\hline & \multicolumn{2}{|c|}{ rsI65774 G>A } & & 0.204 & & 0.086 & & 0.205 \\
\hline & GG & 399 & $18.11 \pm 15.27$ & & $21.96 \pm 17.58$ & & $|3.95 \pm| 6.4 \mid$ & \\
\hline & AG & 238 & $20.22 \pm 14.22$ & & $24.98 \pm 15.50$ & & $15.18 \pm 15.89$ & \\
\hline & $\mathrm{AA}$ & 53 & $21.18 \pm 12.39$ & & $24.49 \pm 20.88$ & & $17.93 \pm|5.7|$ & \\
\hline \multirow[t]{8}{*}{ DRD I } & \multicolumn{2}{|c|}{$\mathrm{rs}|\mathrm{I} 46664| \mathrm{T}>\mathrm{G}$} & & 0.060 & & 0.062 & & 0.169 \\
\hline & TT & 354 & $17.18 \pm 15.65$ & & $20.4 I \pm I 6.56$ & & $|2.95 \pm| 6.4 \mid$ & \\
\hline & TG & 283 & $18.55 \pm 13.58$ & & $23.12 \pm|7.3|$ & & $14.87 \pm 16.07$ & \\
\hline & GG & 53 & $22.10 \pm 12.39$ & & $24.79 \pm 20.33$ & & $16.51 \pm 15.64$ & \\
\hline & \multicolumn{2}{|c|}{ rsll1749676 G>A } & & 0.086 & & 0.419 & & 0.129 \\
\hline & GG & 387 & $18.53 \pm 15.73$ & & $23.89 \pm 16.56$ & & $|2.95 \pm| 6.4 \mid$ & \\
\hline & GA & 238 & $19.91 \pm 13.47$ & & $25.79 \pm 18.06$ & & $14.17 \pm 16.08$ & \\
\hline & $\mathrm{AA}$ & 65 & $21.39 \pm 12.10$ & & $24.58 \pm 20.32$ & & $17.24 \pm 15.59$ & \\
\hline \multirow[t]{12}{*}{ DRD2 } & rs6275 C>T & & & $<0.001 *$ & & 0.422 & & 0.107 \\
\hline & $\mathrm{CC}$ & 154 & $18.48 \pm 14.37$ & & $26.18 \pm 15.92$ & & $18.21 \pm 16.60$ & \\
\hline & $\mathrm{CT}$ & 335 & $26.70 \pm 10.99 * *$ & & $24.23 \pm 20.36$ & & $17.38 \pm 16.16$ & \\
\hline & TT & 201 & $34.21 \pm 9.23 * *, * * *$ & & $26.07 \pm 18.32$ & & $20.43 \pm 15.98$ & \\
\hline & \multicolumn{2}{|c|}{$\mathrm{rs} \mid 801028 \mathrm{C}>\mathrm{G}$} & & $<0.001 *$ & & $<0.00 I^{*}$ & & 0.392 \\
\hline & $\mathrm{CC}$ & 632 & $19.26 \pm 13.82$ & & $|2.95 \pm| 6.4 \mid$ & & $28.44 \pm 16.83$ & \\
\hline & CG & 51 & $33.02 \pm 9.68^{* *}$ & & $27.10 \pm 10.91 * *$ & & $30.56 \pm 19.22$ & \\
\hline & GG & 7 & $35.29 \pm 10.75^{* *}$ & & $30.15 \pm 17.43 * *$ & & $32.33 \pm 18.45$ & \\
\hline & \multicolumn{2}{|l|}{ rs6277 C>T } & & $<0.001 *$ & & 0.675 & & 0.257 \\
\hline & $\mathrm{CC}$ & 554 & $17.20 \pm 13.68$ & & $26.17 \pm 17.44$ & & $15.84 \pm 17.06$ & \\
\hline & $\mathrm{CT}$ & 109 & $22.03 \pm 13.40 * *$ & & $25.51 \pm 17.13$ & & $13.03 \pm 16.25$ & \\
\hline & TT & 27 & $37.81 \pm 14.22^{* * * * * *}$ & & $28.82 \pm 16.92$ & & $13.95 \pm 14.60$ & \\
\hline \multirow[t]{4}{*}{ DRD3 } & \multicolumn{2}{|l|}{$\mathrm{rs} 6280 \mathrm{~T}>\mathrm{C}$} & & 0.101 & & 0.606 & & 0.132 \\
\hline & $\mathrm{TT}$ & 418 & $20.99 \pm 14.04$ & & $26.36 \pm 17.37$ & & $15.31 \pm 16.95$ & \\
\hline & TC & 212 & $22.70 \pm 13.57$ & & $25.37 \pm 17.39$ & & $12.50 \pm 16.42$ & \\
\hline & $\mathrm{CC}$ & 60 & $24.54 \pm 14.78$ & & $24.34 \pm 14.08$ & & $13.88 \pm 14.96$ & \\
\hline \multirow[t]{4}{*}{ DRD5 } & \multicolumn{2}{|l|}{ rs6283 T>C } & & 0.073 & & 0.543 & & 0.424 \\
\hline & TT & 212 & $17.98 \pm 12.98$ & & $26.34 \pm 13.02$ & & $9.67 \pm 11.08$ & \\
\hline & TC & 348 & $19.24 \pm 14.10$ & & $26.85 \pm 18.65$ & & $11.23 \pm 14.97$ & \\
\hline & $\mathrm{CC}$ & 130 & $21.48 \pm 13.75$ & & $24.95 \pm 16.65$ & & $10.78 \pm 14.00$ & \\
\hline
\end{tabular}

Notes: *Significant difference among three groups; $* * P<0.05$, compared with the first row of genotypes for each SNP; ***P<0.05, compared with the second row of genotypes for each SNP.

Abbreviations: COMT, catechol-O-methyltransferase; DRDI, dopamine receptor DI; DRD2, dopamine receptor D2; DRD3, dopamine receptor D3; DRD5, dopamine receptor D5; PANSS, Positive and Negative Syndrome Scale; M, mutant allele; W, wild allele.

efficacy of risperidone might be weak or absent in Chinese schizophrenia patients.

Moreover, the AG genotype of COMT SNP rs165599 exhibited decreased score of negative symptoms of risperidonetreated patients in comparison with genotype AA. These all enriched the evidence that some polymorphisms of COMT had effects on schizophrenia patients' responses to risperidone. However, the study of Fijal et al supported our findings on COMT SNP rs165599, but indicated that COMTrs4680 exerted limited effect on risperidone efficacy for schizophrenics. ${ }^{22}$ There are reasonable explanations for the differences. One is that our study is focused on patients of Han ethnicities, while 
Fijal et al investigated African-American and White patients. Another possible reason may be that candidates in these two studies were treated with different doses of risperidone. Besides, sample size for SNP COMT rs4680 in our study is large enough to support our results.

As for dopamine receptor genes, three SNPs in the DRD2 (rs6275, rs1801028, and rs6277) were all associated with the improvement rates of PANSS total, suggesting that $D R D 2$ played an important role in patients' responses to risperidone. ${ }^{36-38}$ In fact, the reason why therapeutic effects of risperidone worked lies in the balance between occupancies of 5-HT $2 \mathrm{~A}$-receptor and DRD2. ${ }^{39}$ It was also documented that $D R D 2$ alone could regulate the effects of atypical antipsychotics, and the influence of other receptors could be ignored. ${ }^{40}$ Taking rs 1801028 , for example, though risperidone was found to display no distinction in binding affinities for this SNP, the Cys311 variant of rs1801028 was significantly associated with more cAMP synthesis than the corresponding Ser311 variant. ${ }^{38}$ Desensitization and internalization of $D R D 2$ might also be subject to regulation of the proportions of Ser311 and Cys311, which could lead to conformational change of DRD2 with the new disulfide bond established. ${ }^{41}$ Above all, variants of DRD2 would contribute much to functional differences of patients with schizophrenia in response to treatment. With regard to other subtypes of dopamine receptors, no significant link has been found between the SNPs involved and patients' responses to risperidone in this study; but it is still unclear whether polymorphisms of $D R D 1, D R D 3$, and DRD5 participated in risperidone metabolism because just parts of their SNPs were investigated in our study.

There were some limitations in this study. Although 690 schizophrenia patients participated in this trial, a few genotypes (eg, GG of DRD2 rs1801028 and TT of DRD2 rs6277) still have limited carriers, so the reliability of the results was suspected. Besides, the investigated population was constrained to one single ethnicity, so the study result may not be suitable for other ethnicities. Furthermore, the combined effects of COMT and DRD2 on schizophrenia risk were not estimated and their association with PANSS improvement rates after treatment with risperidone also needs to be further explored. Also, linkage disequilibrium between SNPs and haplotype analysis might be added in our further study. Our study has confirmed that the polymorphisms of COMT and $D R D 2$ affected the efficacy of risperidone, but the mechanism still remains unknown. In addition, although we tried different models for each SNP, genetic association with different drugs is not displayed in our study. Thus, further studies are needed to find the possible impacts of the polymorphisms on the metabolic pathway of risperidone so that we would be able to optimize therapeutic strategies for schizophrenics.

\section{Conclusion}

In summary, COMT and dopamine receptor polymorphisms appeared to be critical risk factors for schizophrenia, and they might predict the treatment efficacy of posterior risperidone. All of these findings might provide us with an informative path to better understand the pathology of schizophrenia and serve as a reference for developing early intervention of schizophrenia.

\section{Ethical statement}

This research obtained approval from the ethics committee of Shengjing Hospital of China Medical University and all procedures performed in studies involving human participants were in accordance with the ethical standards of this ethics committee.

\section{Author contributions}

All authors contributed toward data analysis, drafting and critically revising the paper, gave final approval of the version to be published, and agree to be accountable for all aspects of the work.

\section{Disclosure}

The authors report no conflicts of interest in this work.

\section{References}

1. Bowie CR, Depp C, McGrath JA, et al. Prediction of real-world functional disability in chronic mental disorders: a comparison of schizophrenia and bipolar disorder. Am J Psychiatry. 2010;167(9):1116-1124.

2. Makinen J, Miettunen J, Isohanni M, Koponen H. Negative symptoms in schizophrenia: a review. Nord J Psychiatry. 2008;62(5):334-341.

3. Tandon R, Nasrallah HA, Keshavan MS. Schizophrenia, "just the facts" 4. Clinical features and conceptualization. Schizophr Res. 2009; 110(1-3):1-23.

4. Lee MR, Wehring HJ, McMahon RP, et al. Effects of adjunctive intranasal oxytocin on olfactory identification and clinical symptoms in schizophrenia: results from a randomized double blind placebo controlled pilot study. Schizophr Res. 2013;145(1-3):110-115.

5. Sampson S, Hosalli P, Furtado VA, Davis JM. Risperidone (depot) for schizophrenia. Cochrane Database Syst Rev. 2016;4:CD004161.

6. Li Q, Xiang YT, Su YA, et al. Antipsychotic polypharmacy in schizophrenia patients in China and its association with treatment satisfaction and quality of life: findings of the third national survey on use of psychotropic medications in China. Aust N Z J Psychiatry. 2015;49(2):129-136.

7. Foussias G, Remington G. Antipsychotics and schizophrenia: from efficacy and effectiveness to clinical decision-making. Can J Psychiatry. 2010;55(3):117-125.

8. Liang Y, Yu X. The effectiveness and safety of amisulpride in Chinese patients with schizophrenia who switch from risperidone or olanzapine: a subgroup analysis of the ESCAPE study. Neuropsychiatr Dis Treat. 2017;13:1163-1173. 
9. Yasui-Furukori N, Saito M, Nakagami T, et al. Clinical response to risperidone in relation to plasma drug concentrations in acutely exacerbated schizophrenic patients. J Psychopharmacol. 2010;24(7):987-994.

10. Dandash O, Pantelis C, Fornito A. Dopamine, fronto-striato-thalamic circuits and risk for psychosis. Schizophr Res. 2017;180:48-57.

11. Yamaguchi Y, Lee YA, Kato A, Jas E, Goto Y. The roles of dopamine D2 receptor in the social hierarchy of rodents and primates. Sci Rep. 2017;7:43348.

12. Debono M, Newell-Price J. New formulations and approaches in the medical treatment of acromegaly. Curr Opin Endocrinol Diabetes Obes. 2010;17(4):350-355.

13. Zhang JP, Robinson DG, Gallego JA, et al. Association of a schizophrenia risk variant at the DRD2 locus with antipsychotic treatment response in first-episode psychosis. Schizophr Bull. 2015;41(6):1248-1255.

14. Song X, Pang L, Feng Y, et al. Fat-mass and obesity-associated gene polymorphisms and weight gain after risperidone treatment in first episode schizophrenia. Behav Brain Funct. 2014;10(1):35.

15. Huo R, Wei Z, Xiong Y, et al. Association of dopamine receptor D1 (DRD1) polymorphisms with risperidone treatment response in Chinese schizophrenia patients. Neurosci Lett. 2015;584:178-183.

16. Llerena A, Berecz R, Penas-Lledo E, Suveges A, Farinas H. Pharmacogenetics of clinical response to risperidone. Pharmacogenomics. 2013;14(2):177-194

17. Passow S, Thurm F, Li SC. Activating developmental reserve capacity via cognitive training or non-invasive brain stimulation: potentials for promoting fronto-parietal and hippocampal-striatal network functions in old age. Front Aging Neurosci. 2017;9:33.

18. Serata D, Rapinesi C, Kotzalidis GD, et al. Effectiveness of longacting risperidone in a patient with comorbid intellectual disability, catatonic schizophrenia, and oneiroid syndrome. Int J Psychiatry Med. 2015;50(3):251-256

19. Sagud M, Muck-Seler D, Mihaljevic-Peles A, et al. Catechol-Omethyl transferase and schizophrenia. Psychiatria Danubina. 2010 22(2):270-274.

20. Karayiorgou M, Simon TJ, Gogos JA. 22q11.2 microdeletions: linking DNA structural variation to brain dysfunction and schizophrenia. Nat Rev Neurosci. 2010;11(6):402-416.

21. Schizophrenia Working Group of the Psychiatric Genomics C. Biological insights from 108 schizophrenia-associated genetic loci. Nature. 2014;511(7510):421-427.

22. Fijal BA, Kinon BJ, Kapur S, et al. Candidate-gene association analysis of response to risperidone in African-American and white patients with schizophrenia. Pharmacogenomics J. 2009;9(5):311-318.

23. Pelka-Wysiecka J, Wronski M, Jasiewicz A, et al. BDNF rs 6265 polymorphism and COMT rs 4680 polymorphism in deficit schizophrenia in Polish sample. Pharmacol Rep. 2013;65(5):1185-1193.

24. Higashiyama R, Ohnuma T, Takebayashi Y, et al. Association of copy number polymorphisms at the promoter and translated region of COMT with Japanese patients with schizophrenia. Am J Med Genet B Neuropsychiatr Genet. 2016;171B(3):447-457.

25. Hoenicka J, Garrido E, Ponce G, et al. Sexually dimorphic interaction between the DRD1 and COMT genes in schizophrenia. Am JMed Genet B Neuropsychiatr Genet. 2010;153B(4):948-954.

26. Fan H, Zhang F, Xu Y, et al. An association study of DRD2 gene polymorphisms with schizophrenia in a Chinese Han population. Neurosci Lett. 2010;477(2):53-56.
27. Yao J, Pan YQ, Ding M, Pang H, Wang BJ. Association between DRD2 (rs1799732 and rs1801028) and ANKK1 (rs1800497) polymorphisms and schizophrenia: a meta-analysis. Am J Med Genet B Neuropsychiatr Genet. 2015;168B(1):1-13.

28. Betcheva ET, Mushiroda T, Takahashi A, et al. Case-control association study of 59 candidate genes reveals the DRD2 SNP rs6277 (C957T) as the only susceptibility factor for schizophrenia in the Bulgarian population. J Hum Genet. 2009;54(2):98-107.

29. Nunokawa A, Watanabe Y, Kaneko N, et al. The dopamine D3 receptor (DRD3) gene and risk of schizophrenia: case-control studies and an updated meta-analysis. Schizophr Res. 2010;116(1):61-67.

30. Zhao Y, Ding M, Pang H, Xu XM, Wang BJ. Relationship between genetic polymorphisms in the DRD5 gene and paranoid schizophrenia in northern Han Chinese. Genet Mol Res. 2014;13(1):1609-1618.

31. Jonsson EG, Sedvall GC, Nothen MM, Cichon S. Dopamine D4 receptor gene (DRD4) variants and schizophrenia: meta-analyses. Schizophr Res. 2003;61(1):111-119.

32. Huntley D, Baldo A, Johri S, Sergot M. SEAN: SNP prediction and display program utilizing EST sequence clusters. Bioinformatics. 2006; 22(4):495-496.

33. Lachman HM, Papolos DF, Saito T, Yu YM, Szumlanski CL, Weinshilboum RM. Human catechol-O-methyltransferase pharmacogenetics: description of a functional polymorphism and its potential application to neuropsychiatric disorders. Pharmacogenetics. 1996;6(3): 243-250.

34. Lewandowski KE. Relationship of catechol-O-methyltransferase to schizophrenia and its correlates: evidence for associations and complex interactions. Harv Rev Psychiatry. 2007;15(5):233-244.

35. Tybura P, Samochowiec A, Beszlej A, et al. Some dopaminergic genes polymorphisms are not associated with response to antipsychotic drugs in schizophrenic patients. Pharmacol Rep. 2012;64(3):528-535.

36. Lane HY, Lee CC, Liu YC, Chang WH. Pharmacogenetic studies of response to risperidone and other newer atypical antipsychotics. Pharmacogenomics. 2005;6(2):139-149.

37. Yasui-Furukori N, Saito M, Tsuchimine S, et al. Association between dopamine-related polymorphisms and plasma concentrations of prolactin during risperidone treatment in schizophrenic patients. Prog Neuropsychopharmacol Biol Psychiatry. 2008;32(6):1491-1495.

38. Lane HY, Lee CC, Chang YC, Lu CT, Huang CH, Chang WH. Effects of dopamine D2 receptor Ser311Cys polymorphism and clinical factors on risperidone efficacy for positive and negative symptoms and social function. Int $J$ Neuropsychopharmacol. 2004;7(4):461-470.

39. Lai M, Chen W, Zhu H, et al. Low dose risperidone attenuates cueinduced but not heroin-induced reinstatement of heroin seeking in an animal model of relapse. Int J Neuropsychopharmacol. 2013;16(7): 1569-1575.

40. Madras BK. History of the discovery of the antipsychotic dopamine D2 receptor: a basis for the dopamine hypothesis of schizophrenia. J History Neurosci. 2013;22(1):62-78.

41. Chen HT, Ruan NY, Chen JC, Lin TY. Dopamine D2 receptor-mediated Akt/PKB signalling: initiation by the $\mathrm{D} 2 \mathrm{~S}$ receptor and role in quinpiroleinduced behavioural activation. ASN Neuro. 2012;4(6):371-382.
Neuropsychiatric Disease and Treatment

\section{Publish your work in this journal}

Neuropsychiatric Disease and Treatment is an international, peerreviewed journal of clinical therapeutics and pharmacology focusing on concise rapid reporting of clinical or pre-clinical studies on a range of neuropsychiatric and neurological disorders. This journa is indexed on PubMed Central, the 'PsycINFO' database and CAS,

\section{Dovepress}

and is the official journal of The International Neuropsychiatric Association (INA). The manuscript management system is completely online and includes a very quick and fair peer-review system, which is all easy to use. Visit http://www.dovepress.com/testimonials.php to read real quotes from published authors. 